\title{
An editor's tribute to his predecessor
}

\author{
Armin Kurtz ${ }^{1}$
}

Received: 19 November 2015 / Accepted: 20 November 2015 /Published online: 9 January 2016

(C) Springer-Verlag Berlin Heidelberg 2016

At the end of last year, Bernd Nilius stepped down from his position as Editor in Chief of Pflügers Archiv, which he had held for 10 years. Succeeding him in that position is both a great honor and a great responsibility. It will be hard to fill the shoes of such an extraordinary person. Not only is Bernd an outstanding scientist who has made seminal contributions to ion channel physiology [2], he is also a highly educated man with an impressive knowledge of history, philosophy, and literature. Gifted with a talent for the fine arts, he often entertained us, the editorial board, with his brilliant piano skills or with thoughtful essays. An incredibly energetic scholar, he was determined to not only maintain the highest standards for the journal, but also relentlessly devoted himself to improving it. Together with these exceptional features, he impressed us with his enthusiasm for science, in particular for new and exciting developments in the area of physiology. As the leader of the editorial board, he had the unique ability to sense new hot topics and trends, and he made sure they were adequately represented in original articles, reviews, and special issues in our journal, Pflügers Archiv. Our journal's mission is to publish excellent and interesting results in the field of physiological science. The journal's reviewing process, as it stands today, has a well-deserved reputation of being constructive, transparent, timely, and fair-all of which were promoted by Bernd Nilius. Based on the extraordinary depth and breadth of his own research on TRP channels, his tenure as EiC of Pflügers Archiv has had a remarkable impact on the journal's international standing, helping it become a leading journal in the field of physiology. His encyclopedic mind and

Armin Kurtz

armin.kurtz@vkl.uni-regensburg.de

1 Institut für Physiologie, Universität Regensburg, Universitätsstrasse 31, 93040 Regensburg, Germany his deeply rooted sense of loyalty and friendship have also been crucial for the journal's rapidly growing reputation. Bernd successfully bridged the gap between the journal's long history and the requirements of modern physiology publishing. He felt a sense of responsibility towards Eduard Pflüger [1], founder of the world's first physiology journal, which would eventually become the Pflügers Archiv we know today. I also feel obliged to the tradition of our journal, since history is the memory of culture. Thanks to Bernd Nilius' work, I also feel confident that Pflügers Archiv is well prepared to meet the future challenges of scientific publishing. Therefore, I wish to invite and encourage you to continue submitting your interesting and attractive work to Pflügers Archiv. The aims of the journal will not change: we will focus on original research that provides mechanistic insights into physiological functions at the molecular and cellular level. We also welcome submissions concerning the evaluation of molecular and cellular mechanisms of disease, ideally resulting in translational research.

Though the whole editorial board wishes Bernd Nilius all the best for his retirement, he should also know that he will be sorely missed at the helm of Pflügers Archiv.

Dear Bernd, thanks for the many years of great service, and bon voyage!

\section{Armin Kurtz}

\section{References}

1. Nilius B (2014) Eduard Friedrich Wilhelm Pflüger and the Nobel prize. Pflugers Arch 466(11):2019-2020

2. Verkhratsky A, Petersen $\mathrm{OH}$ (2010) Bernd Nilius: the bard of ion channels. Congratulations on 65th birthday. Pflugers Arch 460(4): 691-694 